\title{
A coupled technological-sociological model for national electrical energy supply systems including sustainability
}

\author{
Manfred Benthaus (D)
}

\begin{abstract}
Global trends in the development and use of electricity utilities and assets are practically irreversible. In industrialized nations, capacity factors have grown so large that users may expect freely available electrical potential energy at all times and in almost all locations. Economically capitalizing on this trend means maximizing energy provision and use to boost gross domestic product growth rates. Electricity is now a basic indicator of social development; it is to the cultural-technological dimension what breathing air is to the physiological-biological dimension, the implication being that sustainable development of provision systems has become a matter of international concern.

This article presents a decision basis for the design of sustainable national electrical energy supply systems, incorporating country-specific boundary conditions in the form of user requirements to be specified by users. The basis is a solution space of technologically possible systems, obtained by combining generalized user requirements and physical limitations to generate the solution states. As all technological options for the system are brought under consideration, this approach represents a comprehensive comparative analysis. The decision process ensues by assigning to each solution state a set of (newly defined) system risk factors. Particular consideration is given to evaluating the system's ability to meet the user requirements, i.e., interruption-free provision. The central benchmark is the technological-economic availability. From this is obtained a sustainability boundary, the boundary between quantifiable and unquantifiable economic loss potentials.

This article deliberately avoids referencing specific technological solutions, with the justification that the basis of the user's decision should be independent of technological considerations. The sole exception is a reference to the currently used technology, which forms the starting point.
\end{abstract}

Keywords: Utility, Utilitarianism, Electrical energy supply systems, Cellular energy structures, Electricity supply risks, Availability, Sustainability

\section{Background}

Existing systems of national electrical energy supply use essentially similar technologies. Each system can be decomposed into the structure of the power stations and of the accompanying grid network.

Though the current technology has unquestionably contributed to economic prosperity, it carries a dominant, unquantifiable systemic risk, i.e., of blackouts. Physically speaking, however, for a general system, the risk of blackouts is not inherent and may be avoided. The principle motivation of this article is to incorporate this

Correspondence: manfred.benthaus@googlemail.com

Technische Universität München, Munich, Germany unquantifiable risk into a new strategy for comparing possible designs for future systems in terms of their sustainability.

\section{Electrification as a quantifiable social benefit}

Electrical energy in a form available to humans does not occur significantly in nature and must therefore be provided artificially. By the end of the nineteenth century, humans had amassed sufficient scientific knowledge to develop the national electrical energy supply systems (EESS). Very fundamental technological innovations were needed to implement a functional system.

(c) The Author(s). 2019 Open Access This article is distributed under the terms of the Creative Commons Attribution 4.0 International License (http://creativecommons.org/licenses/by/4.0/), which permits unrestricted use, distribution, and reproduction in any medium, provided you give appropriate credit to the original author(s) and the source, provide a link to the Creative Commons license, and indicate if changes were made. 


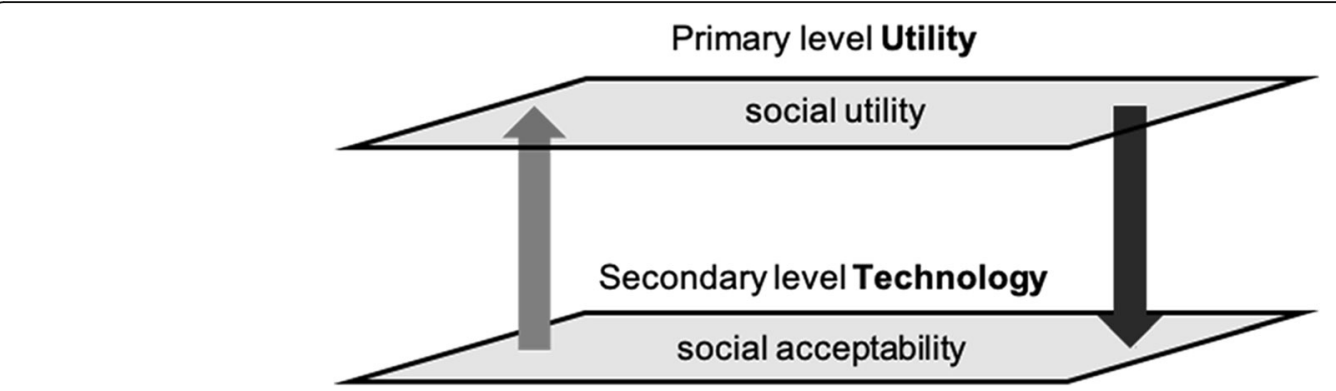

Fig. 1 Model of a social approach to large technological systems

\section{Electrical energy supply}

The implementation and sustainable operation of largescale technological systems depends on majority acceptance by the society in which they are intended to operate. Below, a decision model is developed according to [1], initially consisting of two independent but interacting levels (Fig. 1).

One level decides whether the system has social utility: whether this particular means of electrical energy provision has a positive effect on human well-being, utilitarianism here being the goal-oriented ethics of choice [2].

On the other level, social acceptance is considered, the criteria being investment costs incurred for technology, consequences of technological risk, and consumption of ecological reserves [3].

The levels in the model are not equal. For any system, utility needs be sufficient for consideration, whereas acceptance of the technology is necessary (example: nuclear energy in Germany).

First to be considered is the primary level utility. As early as 1920, the notion of an EESS was semantically raised to an instrument of government: "Communism that is Soviet power plus electrification of the whole country" [4].
The German electricity industry's development in the years from 1890 to 1950 has been examined by [5]. Across the multi-decadal analysis, they arrive at similar results for different forms of government with their respective political forces and currents. The first working hypothesis is as follows:

- The use of electrical energy is independent of the form of government

- The utility of electrification is economically significant

\section{Economic importance}

To test the above working hypothesis about energy consumption, a country's gross domestic product (GDP) is an international economic benchmark that depends on the national consumption of electrical energy (Fig. 2) [6].

The calculated regression function (RF I) shows that rising GDP per capita is characterized by superexponential increase in electricity use. The smallest GDPs per capita in the sample (no use of electrical energy) lie in the region of 1000 USD per capita, and the largest GDPs (for which energy use is unbound) are around 100,000 USD per capita. As energy use rises, its

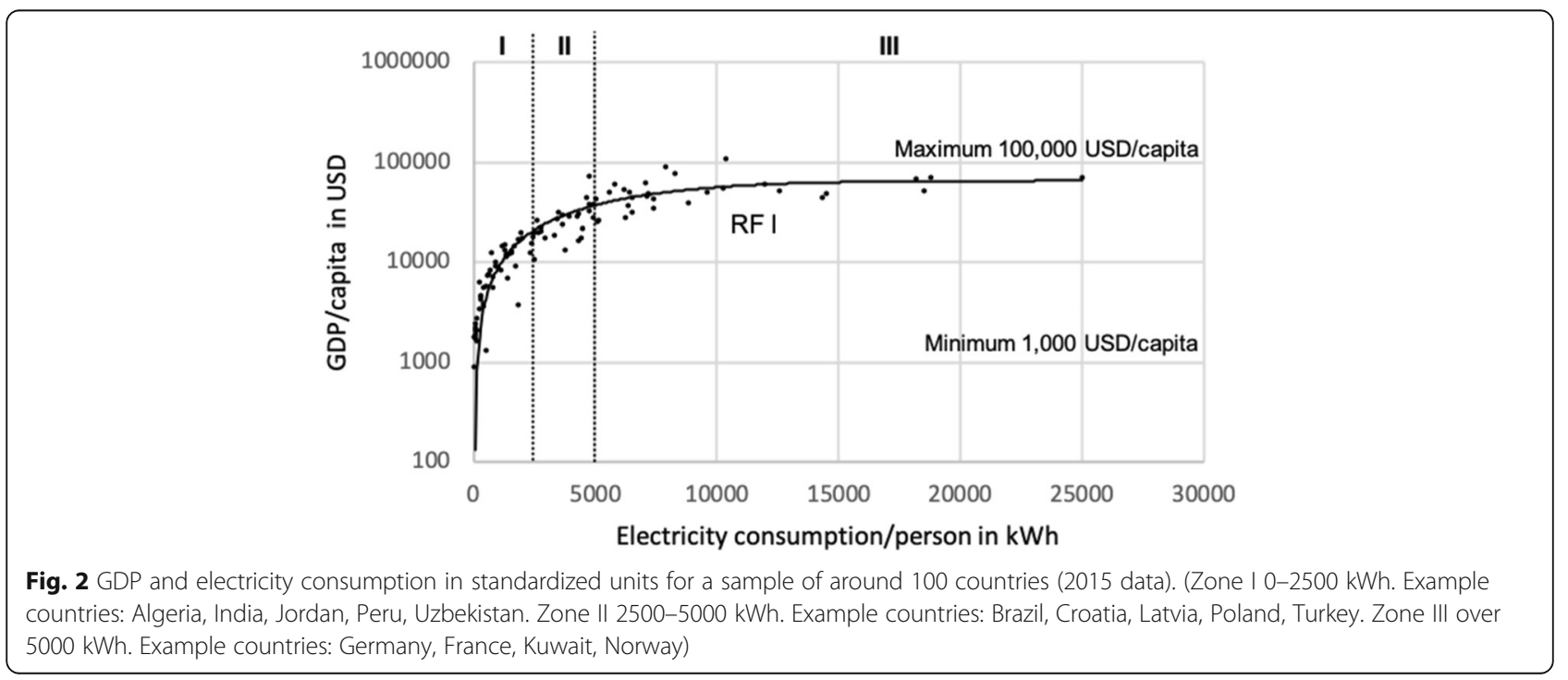




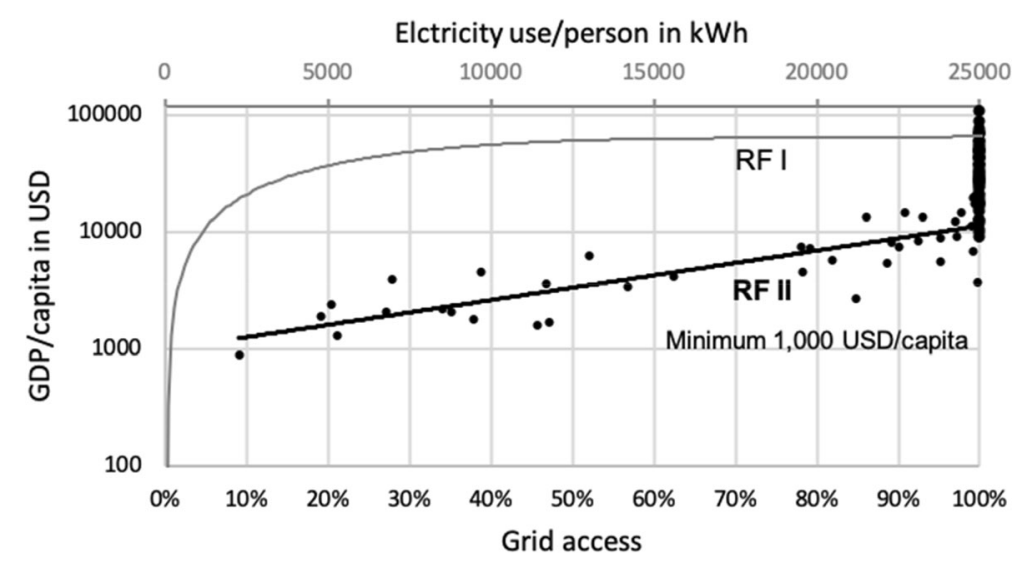

Fig. 3 Normalized GDP and relative electricity grid access for around 100 countries. Grid access data from 2014. Same country sample as Fig. 2

direct influence on GDP decreases sharply. Even in the saturation zone (zone III), though, there is exponential increase.

Figure 2 also shows that as energy use increases, the spread of individual countries' GDP per capita increases significantly, which is reasonably assumed to originate from country-specific factors independent of electrical energy use.

Comparison of the countries with high and low GDP per capita indicate that electrical energy use has a social utility in the utilitarian sense, which, on considering the dataset as a whole, appears to be independent of social structure.

We therefore accept the first working hypothesis.

Key point 1: Provision of electrical energy is associated with utility to national economies that is independent of the type of society

Key point 2: The GDP per capita that is attainable without the use of electrical energy is about $1 \%$ of that estimated with unrestricted use of energy and national electrification is therefore economically significant

\section{Current electrical energy supply}

In 2013, the volume of electrical energy used worldwide was approximately 20,000 billion $\mathrm{kWh}$, with an average growth of 400 billion kWh per year since 1980 [7]. To provide these amounts of energy, a single technology is currently being used: a combination of centralized large-scale electricity generation plants and comprehensively connected large-scale networks.

\section{Economic importance}

Access of a country's population to an electricity grid and the associated opportunities has direct impact on GDP. Figure 3 depicts the situation as described by $[6,8]$.

\footnotetext{
${ }^{1} \mathrm{AR} / \mathrm{AU} / \mathrm{BE} / \mathrm{CA} / \mathrm{CH} / \mathrm{CL} / \mathrm{CN} / \mathrm{CN} / \mathrm{DK} / \mathrm{DE} / \mathrm{ES} / \mathrm{FI} / \mathrm{FR} / \mathrm{GB} / \mathrm{GR} / \mathrm{HU} / \mathrm{IE} / \mathrm{IT} /$ $\mathrm{KR} / \mathrm{LU} / \mathrm{MY} / \mathrm{NZ} / \mathrm{NL} / \mathrm{NO} / \mathrm{PL} / \mathrm{PT} / \mathrm{RO} / \mathrm{RU} / \mathrm{STR} / \mathrm{UA} / \mathrm{US}$

${ }^{2}$ Union for the Coordination of the Transmission of Electricity, currently part of ENTSO-E

${ }^{3}$ There are different interpretations of supply quality; from User Requirements for a Cellular Grid, availability is used in the sense of [34]
}

The new regression function (RF II) is a standard exponential function over the defined range for relative electricity grid access and GDP. As in RF I, the minimum point is $0 \%$ access and USD 1000 GDP per capita. RF I increases most in zone I $(0-2500 \mathrm{kWh})$, and RF II reaches 100\% access before the GDP in RF I flattens out. From this, it can be concluded that worldwide use of electrical energy takes place via access to electricity grids.

This is supported by considering a sample from the group of countries with $100 \%$ network access. ${ }^{1}$ Of global energy consumption, their share alone (2013) is more than $80 \%[6,9]$.

\section{Technology}

These energy supply systems are based on Faraday's law of induction; specifically, they are three-phase systems. Existing systems have no significant storage of electrical energy; therefore, the demand must be generated "ontime." The technological basis of this is power-frequency control, with a common operating frequency (e.g., 50 $\mathrm{Hz}$ ) as the central control variable.

The fundaments are described in $[10,11]$.

The task of electricity grids is to connect all users with all producers and to transmit the required energy with as little loss as possible. Technologically, this is a major challenge.

Three-phase technology allows the implementation of a fine grid structure that is differentiated by voltage level. The national grid is at the highest voltage. It is a functional link to the lower-level networks and is a

\footnotetext{
${ }^{4}$ Unplanned interruptions including all events; the longest was 11.6 $\mathrm{min} / 908 \mathrm{~min}$ in 2014

${ }^{5}$ Example: UCTE network area/cf. technological possibility solution space, substantial systemic risk, defining social sustainability 6Example: German 'Energiewende' towards wind energy and photovoltaic systems
} 
significant "electrical network node" in the system. In Europe, the national high-voltage grids have been merged to form an international interconnection grid. This integration has lead towards a European copper plate, with the largely political goals of increasing the physical exchange of electricity and improving technological supply reliability. One example is the UCTE grid area, ${ }^{2}$ which consists of the coupled three-phase networks of 24 countries in central Europe [12]. In this grid region, 440 million users are supplied with electricity: an economic power of 13,000 billion USD (annual figures for 2016). The initiator is the European Union, having outlined the creation of an internal electricity market [13].

Supply reliability and quality ${ }^{3}$ is an important system descriptor, for which multiple technical indexes have been devised.

1. The SAIDI (System Average Interruption Duration Index) belongs to a group of internationally recognized indicators and describes "...the average interruption in supply per connected final consumer within a calendar year..." [14]. This is a regulatory determination of the supply situation based on past experience. In a 2014 international benchmarking, the SAIDI values were calculated for 27 European countries [15]. The average total annual interruption was $170 \mathrm{~min}$ for the $8760 \mathrm{~h}$ of a normal year ${ }^{4}$; the average power availability for the end customer is $99.97 \%$. This result can be interpreted favorably, but it raises several questions.

- Have technological choices led to excessive costs for the users?

- Are there cheaper technologies with equivalent availability?

- Is it appropriate to base indicators on past performance?

2. Direct electrical parameters such as short-circuiting [16] also have an effect on the supply quality. The aim is to create a system that is fair for all users, with the highest possible performance. This is a mounting challenge, however, with a growing grid and a change in generation technology, stemming from the move to inverter-based sources and away from direct feed-in via rotating masses [17]. ${ }^{6}$

3. Blackouts have the most immediate effect on availability [18]. These occur when fluctuations in the power-frequency control exceed or fall below specified frequency values. In the UCTE grid area, these limits are $50 \mathrm{~Hz} \pm 2.5 \mathrm{~Hz}$ [19]. Outside the range, no power plants remain on-grid and the national EESS is functionless. Blackouts can have a range of causes-extensive, sustained blackouts are caused by software and/or hardware irregularitie$\mathrm{s}$-and risk is inherent to the system, as explored in later sections. Some countries, such as Switzerland, treat blackouts as national hazards [20], paralleling the earlier quotation from Lenin.

\section{Opportunity-risk profile}

Grid technology successfully provides electrical energy to users, not only a single national economy but also the world over, and has led to significant global economic growth.

Despite this, the inherent risks can be seen reflected in the supply quality of any one of these grids. Large-scale, sustained functional losses are possible at any time and can have considerable economic impact: "As an Austrian study has found, for an Austria-wide power failure of 24 hours, damage of at least 1 billion Euros, likely several billion Euros" [21].

The opportunity-risk profile of the technology currently used worldwide thus diverges wildly. The economically quantifiable positive effect on national GDP is contrasted with non-quantifiable risk.

Key point 3: Large-scale production plants in combination with large-scale grids are the central technologies of EESS worldwide and are drivers of positive economic development

Key point 4: Inherent systemic risks can at any time result in large-scale failures of unlimited duration

\section{User requirements for a cellular grid}

The starting point for the analysis is demand and use. First, EESS user requirements are formulated qualitatively. The requirements are then described quantitatively in cellular structures.

\section{Requirements}

Seven ad hoc system requirements are formulated that give structure to the "utility" level of the social acceptance model:

1. A utilitarian approach is taken, due to the large number of users;

2. Electrical energy consumption is meant in the anthropogenic sense;

3. The location of energy use is freely selectable by each user;

4. The time profile of energy use is freely selectable by each user;

5. Each user is limited to a freely selectable, fixed maximum energy use;

6. At any time, energy use equals energy demand;

7. Supply costs are economically minimized.

Later, an ancillary requirement will be derived. 


\section{Energy functions}

The energy demand function $E^{D}$ with $i, i_{0} \in I, i \leq i_{0} ; t \in T$, and $\boldsymbol{x}_{i} \in N \subset R^{3}$ is defined as

$$
\begin{aligned}
& E^{D}:(T \times N) \rightarrow I R^{+} \\
& \quad\left(t, \boldsymbol{x}_{i}\right) \rightarrow E^{D}\left(t, \boldsymbol{x}_{i}\right) .
\end{aligned}
$$

Location vectors $\boldsymbol{x}_{i}$ uniquely define the $i$ th user location and the time component of individual user behavior. The function can be written as

$$
E^{D}\left(t, \boldsymbol{x}_{i}\right)=E_{\max }^{D}\left(\boldsymbol{x}_{i}\right) \cdot f_{i}^{D}(t),
$$

(short form)

$$
E_{i}^{D}(t)=E_{\max , i}^{D} \cdot f_{i}^{D}(t) .
$$

with $E_{\max , i}^{D}$, the maximum energy and $f_{i}^{D}: T \rightarrow[0 ; 1]$ a differentiable time function.

The function applies to the primary "utility" level.

There exists no natural energy source with the system requirements, meaning energy must be generated and provisioned anthropogenically. For this, there is the energy supply function $E^{S}$ :

$$
\begin{aligned}
E^{S}: & (T x N) \rightarrow I R^{+}, \\
& \left(t, \boldsymbol{x}_{i}\right) \rightarrow E^{S}\left(t, \boldsymbol{x}_{i}\right),
\end{aligned}
$$

(short form)

$$
E_{i}^{S}(t)
$$

The variables here have the same meanings as in Eqs. 1 and 2, and the function should be analytic for each location in the time variable.

The supply energy function is part of the secondary "technology" level. The short form will be used in the technological function in Technological Possibility Solution Space.

\section{Microcell}

The functions in Eqs. 1 and 3 operate on different levels of the model. Equating them mathematically, we can define the initial balance between them. For each location,

$$
E_{i}^{D}(t)=E_{i}^{S}(t) \rightarrow \int_{t} E_{i}^{D}(t) d t=\int_{t} E_{i}^{S}(t) d t .
$$

This defines an energy microcell (microcell for short), the smallest energy unit in a national EESS. It incorporates user requirements $2,3,4,5$, and 6 .

\footnotetext{
${ }^{7}$ In principle, bundling applies to all aspects from physical connection to the creation of the virtual network. Here, only physical connections are considered (referred to as technological macrocells).
}

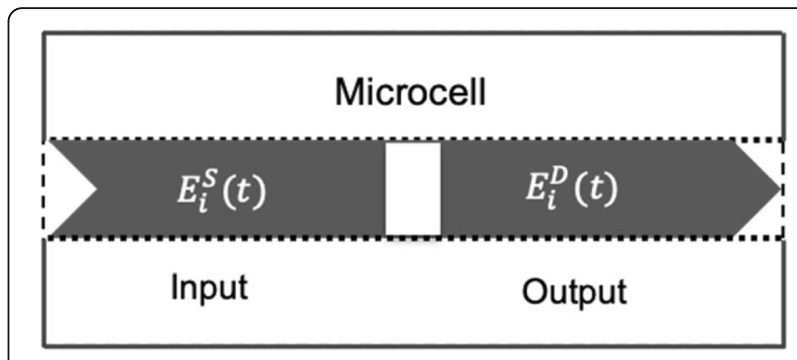

Fig. 4 Elementary energy cell at location $\boldsymbol{x}_{i}$

\section{Macrocell}

To get a handle on the more complex system states, it is greatly helpful to bundle the microcells. ${ }^{7}$ Total supply and demand energies for an ensemble can be calculated for a system with $j_{0}$ microcells using Eq. 4:

$$
E_{j_{0}}^{D}(t)=\sum_{j=1}^{j_{0}} E_{j}^{D}(t) \text { and } E_{j_{0}}^{D}(t)=\sum_{j=1}^{j_{0}} E_{j}^{S}(t) .
$$

The energy balance equation follows

$$
E_{j_{0}}^{D}(t)=E_{j_{0}}^{S}(t) \rightarrow \int_{t} E_{j_{0}}^{D}(t) d t=\int_{t} E_{j_{0}}^{S}(t) d t
$$

This defines the energy-economic macrocell (or macrocell for brevity).

\section{National macrocell}

If the ensemble is extended to all $i_{0}$ users ${ }^{8}$ of a national EESS, a national energy macrocell (or national macro$c e l l$ ) is created. This has the following energy relation.

$$
\begin{aligned}
E_{\text {Nat. }}^{D}(t) & =\sum_{i^{\prime}=1}^{i_{0}^{\prime}} E_{i^{\prime}}^{D}(t)+\sum_{j=1}^{j_{0}} E_{j_{0}}^{D}(t) \\
& =\sum_{i^{\prime}=1}^{i_{0}} E_{i^{\prime}}^{S}(t)+\sum_{j=1}^{j_{0}} E_{j_{0}}^{S}(t) \\
& =E_{\text {Nat. }}^{S}(t),
\end{aligned}
$$

(short form)

$$
E_{\text {Nat. }}^{D}(t)=E_{\text {Nat. }}^{S}(t) \rightarrow \int_{t} E_{\text {Nat. }}^{D}(t) d t=\int_{t} E_{\text {Nat. }}^{S}(t) d t .
$$

The energy demand term in the microcells (the output of Fig. 4) is invariant for different system designs. Freedom in the design of the system is captured in the supply term.

Key point 5: Formulation of qualitative user system requirements

Key point 6: Definition and properties of supply and demand energy functions

Key point 7: Definition and properties of energy micro- and macrocells and the national macrocell

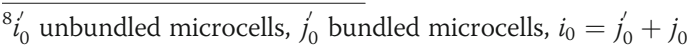




\section{Physical limitations and possibilities}

The primary "utility" level in the social acceptance model is now somewhat structured and ready to be coupled to the secondary "technology" level. A mezzanine level is introduced to define the coupling (Fig. 5). It should highlight the scientific possibilities and limits that affect both user requirements and possible technological solutions. Bilateral feedback is necessary between primary and mezzanine levels (cf. Electrification as a Quantifiable Social Benefit, the primary level takes precedence). One-way coupling suffices between mezzanine and secondary levels.

The analysis proceeds with aspects from classical field theory, specifically from classical electrodynamics.

The limits of physical possibility for a national electrical energy supply system are determined by the principle of relativity, Maxwell's equations, the associated conservation laws, and macroscopic electromagnetism and the propagation of electromagnetic waves. Detailed treatments of these topics can be found in [22-24]. Here, relevant principles are established such as are necessary here.

\section{The principle of relativity}

The most important consequence of relativity for the present case is the finite propagation speed of forces and information (the speed of light in vacuum). It follows that all dynamic physical systems have time lags so that the balance requirement in Eq. 4 yields the relation.

$$
E^{D}\left(t, \boldsymbol{x}_{i}\right) \cong E^{S}\left(t^{\prime}, \boldsymbol{x}_{i}\right)
$$

with

$$
t^{\prime}=t+\Delta t
$$

This formulation also expresses the weighting of the primary and secondary levels: the time shift effect is associated to the supply energy. ${ }^{9}$

\section{Conservation laws}

Energy and momentum are conserved in isolated systems, in this case a system of charged particles and electromagnetic fields. Poynting's theorem [25] is a statement of energy conservation and is given here in the form of a balance equation

$$
\frac{\partial u}{\partial t}+\nabla \cdot \boldsymbol{S}=-\boldsymbol{J} \cdot \boldsymbol{E}
$$

This equation also defines the Poynting vector, which describes the energy flux density of the electromagnetic field.

\footnotetext{
${ }^{9}$ Ultimate goal of the European copper plate is to allow providers to meet e.g. Warsaw's demand with supply generated elsewhere e.g. in Madrid (UCTE grid area cities). The signal crosses the intervening $4600 \mathrm{~km}$ in approx. $15 \mathrm{~ms}(75 \%$ of the wave period at $50 \mathrm{~Hz})$.
}

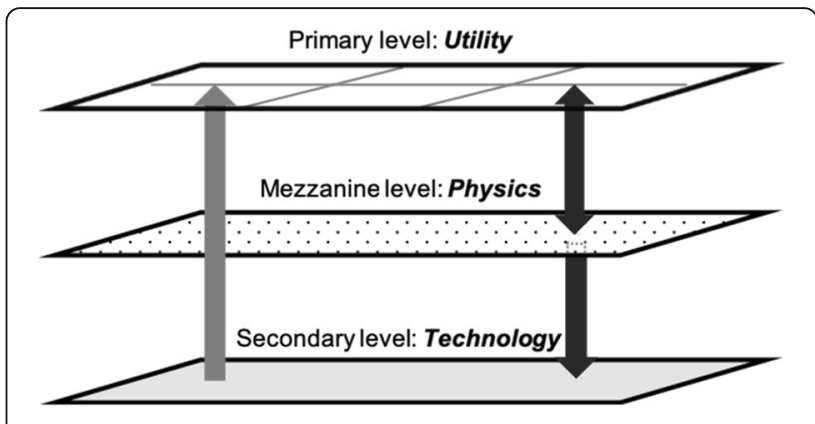

Fig. 5 Extension of the model by structuring the coupling between primary and secondary levels with a mezzanine level

$$
\mathbf{S}=\mathbf{E} \times \mathbf{H}
$$

In the case of anthropogenic energy transmission by means of electromagnetic waves, radiation losses are of secondary importance due to the low field frequencies. The signal velocity itself is already maximized: it is the speed of light [26]. Conservation of electric charge is encoded in the continuity equation [27]

$$
\frac{\partial \varrho}{\partial t}+\nabla \cdot \mathbf{J}=0
$$

\section{Spatial distances}

Spatial remoteness in the sources and sinks of electric charge is not unusual in electrodynamics; indeed, the function of electromagnetic fields is to connect them. The intervening medium determines the speed of light $c$ and, therefore, the signal velocity. The associated time shift $\Delta t$ is directly proportional to the separation $\Delta \boldsymbol{x}$, with

$$
\Delta t=\frac{|\Delta \boldsymbol{x}|}{c} .
$$

This inevitable delay contradicts the requirement on the microcells in Eq. 4 that supply and demand energies should have precisely zero time shift.

\section{Parallel circuits}

Electricity sources are here assumed to be current sources. Ideal current sources feed current into a connected network independently of the load, or equivalently, can continuously draw from an infinitely large energy reserve without disruption. In reality, ideal sources must be forgone for real sources, with time shifts and finite energy reservoirs [28].

As currents must be superimposed without violating charge conservation (Eq. 11), two-terminal parallel networks must be linear. When current sources (ideal or real) are connected in parallel, their currents add up to a new total current (Kirchhoff's node law), tantamount to a new equivalent current source.

Key point 8: Finiteness of signal propagation in physical systems 
Key point 9: Compliance with charge, energy, and momentum conservation laws

Key point 10: Option 1 is to allow spatial remoteness of source and sink; option 2 is to allow parallel connection of sources

\section{Technological Possibility Solution Space}

So far, in the social acceptance model, some structure has been given to the primary level, a mezzanine level has been introduced and structured, and the resulting interactions developed. In this section, the secondary level is given some features, resulting in a set of technologically possible solutions.

\section{Supply energy}

The structure of the secondary "technology" level is determined by the supply energy $E^{S}$. It is analytical in the variable $t$ and may therefore be expanded in a Taylor series (cf. User Requirements for a Cellular Grid, Eq. 3). For each location of $x_{i}$,

$$
\begin{aligned}
E_{i}^{S}\left(t_{i}^{\prime}\right)= & E_{i}^{S T}(t)+\frac{\partial E_{i}^{S T}(t)}{\partial t} \cdot \Delta t_{i}+\frac{1}{2} \frac{\partial^{2} E_{i}^{S T}(t)}{\partial t^{2}} \\
& \cdot \Delta t_{i}^{2}+R_{3}\left(t_{i}^{\prime}\right) .
\end{aligned}
$$

Definitions:

- Time shift $\Delta t_{i}=t_{i}^{\prime}-t$ in the $i$ th microcell;

- The zeroth order term describes a constant supply energy level at time $t$;

- The first order term contains the temporal derivative of energy, i.e., power $P^{S}\left(t, x_{i}\right)$;

- The second order term contains the power dynamics $P_{i}^{S}(t)$; and

- The third term contains higher order derivatives.

A national EESS is described by the following system of equations, in which higher order terms are neglected

$$
\begin{gathered}
E_{1}^{D}(t) \cong E_{1}^{S}\left(t_{1}^{\prime}\right) \cong \quad E_{1}^{S T}(t)+\frac{\partial E_{1}^{S T}(t)}{\partial t} \cdot \Delta t_{1}+\frac{1}{2} \frac{\partial^{2} E_{1}^{S T}(T)}{\partial t^{2}} \cdot \Delta t_{1}^{2} \\
: \\
E_{i_{0}}^{D}(t) \cong E_{i_{0}}^{S}\left(t_{i_{0}}^{\prime}\right) \cong \quad E_{i_{0}}^{S T}(t)+\frac{\partial E_{i_{0}}^{S T}(t)}{\partial t} \cdot \Delta t_{i_{0}}+\frac{1}{2} \frac{\partial^{2} E_{i_{0}}^{S T}(t)}{\partial t^{2}} \cdot \Delta t_{i_{0}}^{2}
\end{gathered}
$$

Each equation describes a microcell. Macrocells can then be created by combining corresponding rows. The right hand side of the system of equations encodes the possible technological design variables (cf. User Requirements for a Cellular Grid). For Germany, $i_{0}$ is approximately 45 million.

\section{The structure variable}

To ensure satisfaction of Equation System 14, five system-defining technological structural variables (S1S5) are devised.
$S_{1}$-time shift, $\Delta t \rightarrow 0$.

The lag between energy use and supply has two components: relativistic, $\Delta t_{r}$, and non-ideal current source effects, $\Delta t_{s}$.

For the $i$ th microcell, linear superposition $\Delta t_{i}$ gives

$$
\Delta t_{i}=\Delta t_{r_{i}}+\Delta t_{s_{i}} .
$$

A technological macrocell is a collection of $j_{0}$ microcells and has a total time shift $\Delta t_{j_{0}}$, which may be compared with the equivalent value for the microcells $\sum_{i=1}^{j_{0}} t_{i}$. The smaller of the two better fulfills the user requirements.

$S_{2}$-stationary system states, $E_{i}^{S T}(t)=c_{i}$

Any energetically possible stationary state of a microcell can be demanded at a given time. Equation System 14 has the following condition for stationary states

$$
E_{i}^{D}=E_{i}^{S}=E_{i}^{S T}=c_{i} .
$$

Kirchhoff's node rule implies that superposition applies to macrocells, written as

$$
E_{j_{0}}^{S T}=\sum_{j=1}^{j_{0}} E_{j}^{S T}=\sum_{j=1}^{j_{0}} c_{j} .
$$

$S_{3}$-power output of current sources, $P_{i}^{S}(t) \rightarrow \infty$

The finite power output of real sources varies over finite time intervals as the temporal gradient of the supply energy. The greater the gradient at a stationary operating point $E_{i}^{S T}(t$ ), the shorter the necessary adjustment time interval $\Delta t_{s_{i}}$. The source output must be technologically forced towards the ideal value. This applies to microcells and macrocells and is therefore relevant to the whole system (cf. Current Electrical Energy Supply, reducing the system's short-circuit power).

$S_{4}$ - power dynamics of current sources, $P_{i}^{S}(t) \rightarrow \infty$

The requirements on the power dynamics of the sources mirror those from $S_{3}$. Deviations are small, bounded by the time adjustment interval $\Delta t_{i}^{2}$. To achieve significant dynamics is a particular technological challenge under the formulated economic boundary conditions. The situation applies equally to microcells and macrocells and is, like power output, a key element in system choice.

$S_{5}-$ maximum power of a national EESS, $\wp_{\text {Nat. }}^{D}$

Making use of the mean value theorem, the energy demand function defined in Eq. 2 must have a maximum. For the $i$ th microcell, with $t_{0} \in T$,

$$
P_{i}^{D_{\max }}:=E_{\max , i}^{D} \cdot \frac{\partial f_{i}^{D}\left(t_{0}\right)}{\partial t},
$$

and Eq. 4 gives the power relation

$$
P_{i}^{D_{\max }}=P_{i}^{S_{\max }} .
$$

Free individual user behavior is given by a function $f_{i}^{D}$, and the system must be capable of providing the 


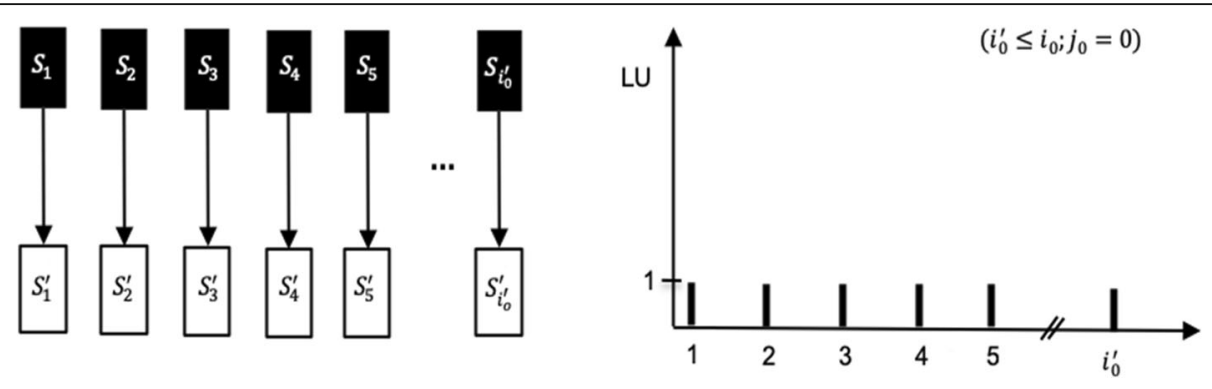

Fig. 6 Base module I: schematic and associated grid spectrum

maximum required power at any time. Because hardware should lie comfortably in the realm of adequacy for any demand placed on it, hardware is the main driver of cost.

For a technological macrocell consisting of $j_{0}$ microcells, the balance equation is obtained by summation

$$
\begin{aligned}
\wp_{\text {macrocell }}^{D} & =\sum_{j=1}^{j_{0}} P_{j}^{D_{\max }}=P\left(j_{0}\right)=P\left(k_{0}\right) \\
& =\sum_{j=1}^{j_{0}} P_{j}^{S_{\max }}=\wp_{\text {macrocell }}^{S} .
\end{aligned}
$$

The two physical possibilities for the system discussed earlier are a parallel connection of sources and spatial remoteness of source and sink. These are two technological degrees of freedom in the macrocell and degrees of system design freedom-together with options for the number and size of sources. If there are $k_{0}$ current sources, only the power relation $P\left(j_{0}\right)=P\left(k_{0}\right)$ applies and the freedom lies in $k_{0}$, with $1 \leq k_{0} \leq j_{0}$. For a national macrocell,

$$
\wp_{\text {Nat. }}^{D}=\sum_{j=1}^{j_{0}} P_{j}^{S_{\max }}+\sum_{i^{\prime}=1}^{i_{0}^{\prime}} P_{i}^{D_{\max }}
$$

The above five parameters comprise the initial structure vector $S^{*}$

$$
\boldsymbol{S}^{*}=\left(S_{1} ; S_{2} ; S_{3}, S_{4} ; S_{5}\right)
$$

\section{Base modules}

Energy is exchanged between source and sink in the form of electromagnetic waves, which require material connection suitable for the high energy fluxes of an EESS [29]. Physically, this can be interpreted as meaning that upon request, a Poynting vector ${ }^{10}$ is transmitted along the conductive material to the destination. Such a structure is referred to as a power grid or simply grid. Grids are defined by paths in the three-dimensional Euclidean vector space, mathematically described by a metric space and its special properties (cf. Additional file 1).

A second working hypothesis can now be formulated:

\footnotetext{
${ }^{10}$ cf. Physical Limitations and Possibilities; Appendix IV. Here only the magnitude of the Poynting vector was used.
}

- Operation of the system without a grid and without source bundling is impossible

- Operation of the system with a grid but without source bundling is useless

As a result, the two physical options are combined into a single usable technology, to which electricity generation is primary and the grid is secondary. Seen economically, this is a two-stage production process whose sub-processes are technologically different.

The following section introduces two base modules from which each technological system state can be generated (cf. Additional files 1 and 2).

\section{Base module I}

The base module I consists only of singular microcells $i_{0}$ so that $i_{0} \leq i_{0} ; j_{0}=0$. Source requirements are given by Eqs. 4, 8, and 19. For the $i$ th microcell, the source is at $\boldsymbol{x}_{i}^{\prime}$ and the sink at $\boldsymbol{x}_{i}$ with $\boldsymbol{x}_{i^{\prime}} \approx \boldsymbol{x}_{i}$. The network is a microgrid within the metric space $\left(N_{i^{\prime}}, d_{i^{\prime},|.|}\right)$, with an associated conductivity function.

The mathematical concept of connectedness of subsets underlies the grid structure. For base module I, each individual microcell is connected, and the $i_{0}^{\prime}$-microcell ensemble is pairwise disconnected.

Grid spectra show connection lengths within a grid. Figure 6 shows the system structure of base module I and the resulting grid spectrum.

\section{Base module II}

Base module II consists of bundled microcells $j_{0}$ with $i_{0}^{\prime}=0$; $j_{0} \leq i_{0} ; k_{0}<j_{0}$. Meeting the source requirements proceeds differently for base module II than for base module I. The 1:1 source-sink fraction in base module I is replaced with $k_{0}, k_{0}<$ $j_{0}$, new equivalent current sources based on parallel connections. The equivalent current sources are located at $\boldsymbol{x}_{1}, \ldots, \boldsymbol{x}_{k_{0}}$ and the sinks at $\boldsymbol{x}_{1}, \ldots, \boldsymbol{x}_{j_{0}}$. Location vectors are unique, and the distances are, as before, significant. The network is a macrogrid. The grid is carried by the metric space $\left(N_{n_{0}}, d_{n_{0}}\right)$ 

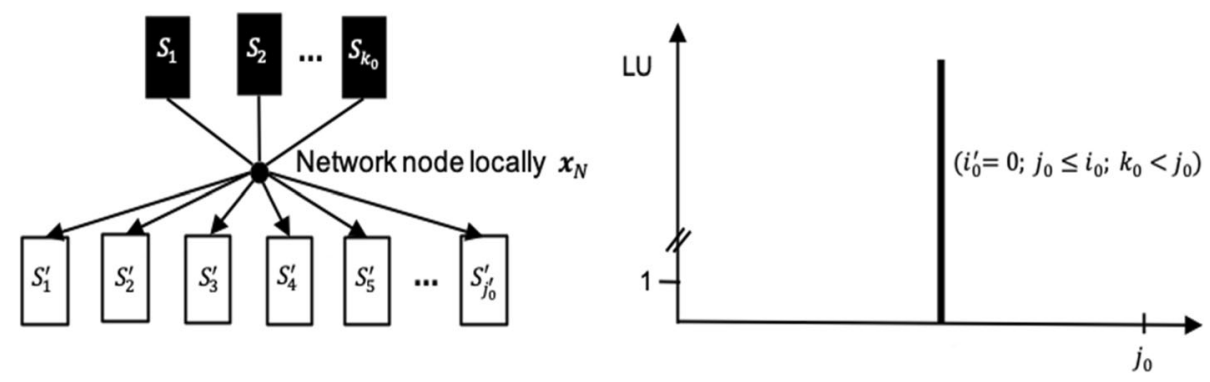

Fig. 7 Base module II: schematic and associated grid spectrum

based on the French railway metric, with additional location vector $\mathbf{x}_{N}$. In this metric, the ensemble containing $j_{0}$ microcells and $k_{0}$ current sources is globally connected. Figure 7 depicts a schematic of base module II and the associated grid spectrum.

For this module, some additional electrical observations may be made. First, note that the total supply energy is obtained from a single equivalent current source $k_{0}=1$. Thus, there exists at least one network node. At all times, the entire energy flux of the macrocell is passing through this node. The grid structure corresponds to one such equivalent node (cf. Current Electrical Energy Supply).

\section{System degrees of freedom: energy demand}

The user requirements and technological degrees of freedom add their own dimensions to system design. The choice of any technological "option" has associated sociological consequences, as can be demonstrated with the base modules.

\section{Base module I}

All microcells are by design electrically independent of each other, with the sociological consequence that the decision about a microcell's technological design lies exclusively with the microcell user. He is thus solely responsible for the business costs of his decision.

There is no technological-economic socialization.

\section{Base module II}

In this module, all microcells are connected to form a macrocell, meaning all microcells are electrically interdependent. The sociological effect of this is to pass decision-making authority from the individual user to a third party. This determines the business characteristics, and resulting costs remain in the user group.

In this module, there is technological-economic socialization.

The above are structural features of the secondary "technology" level.

\section{System states and technological solution space}

System states describing technologically possible configurations for a national system are denoted by state vectors (cf. Additional file 2). The state vector components are, for now, the number of microcells not connected in parallel $i_{0}^{\prime}$, the number of technological macrocells $n_{0}$, the number of parallel-connected microcells $j_{0}^{*}$, and the number of parallel-connected equivalent current sources $k_{0}^{*}$. They are real vectors in the set.

$$
\Omega_{u}:=\left\{\boldsymbol{u} \in R^{4} \mid \boldsymbol{u}=\left(i_{0}^{\prime} ; n_{0} ; j_{0}^{*} ; k_{0}^{*}\right)\right\} .
$$

The state space $\Omega_{u}$ is the solution space of all technologically possible configurations. Two of the state variables, the numbers of parallel-connected microcells and of equivalent current sources, are functionally dependent, so for constant $j_{0}^{*}$ and $k_{0}^{*}$, cellular variety is possible across the $n_{0}$ technological macrocells.

This manifests as additional state vectors, so-called fine structure vectors. Properties of $\Omega_{u}$ can be deduced. Like the base modules, each state vector has a grid spectrum.
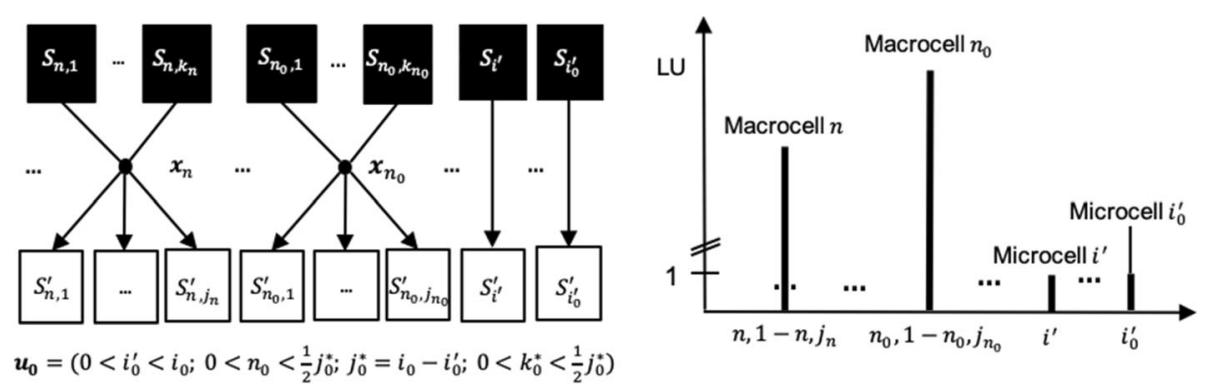

Fig. 8 National EESS $\left(u_{0}\right)$ - schematic and associated grid spectrum 
Figure 8 shows a polychromatic-state based on the combinations of the base modules. The possible states $\boldsymbol{u}_{0}$ are members of $\Omega_{u_{0}}$.

In addition, there are two further monochromatic states given by the base modules I and II as national EESS (Table 1).

The technological solution space is built from these subsets

$$
\Omega_{u}=\Omega_{u_{0}} \cup \Omega_{u_{I}} \cup \Omega_{u_{I I}}
$$

and the component representation of a general vector $\boldsymbol{u} \in \Omega_{u}$ is

$$
\boldsymbol{u}=\left(0 \leq i_{0}^{\prime}<i_{0} ; 0 \leq n_{0}<\frac{1}{2} j_{0}^{*} ; j_{0}^{*}=i_{0}-i_{0}^{\prime} ; 0 \leq k_{0}^{*}<\frac{1}{2} j_{0}^{*}\right)
$$

A sensible question at this stage is whether $\Omega_{u}$ is mathematically complete, that is, whether all possible states are in $\Omega_{u}$. Without going into a rigorous mathematical proof, completeness will be demonstrated by means of the grid spectra and the state vectors.

The grid spectra of the base modules shown in Figs. 6 and 7 represent the extreme states. The spectra do not fundamentally change in transition to monochromatic states, implying the monochromatic states are extreme. Since $u_{0}$ is any polychromatic state, the associated spectra must lie between these extremes.

The state vector components are indexed with natural numbers; since all indexes are defined by their being possible, the resulting state vector set is also complete.

Therefore the technological solution space is complete, providing the basis for a decision on the preferred national EESS now looking to the user requirements. $^{11}$

Key point 11: Declaration of technological structural variables

Key point 12: Introduction of base modules

Key point 13: Definition of a power grid structure and associated grid spectra

Key point 14: Reduction of national EESS to state vectors and their solution set

\section{Substantial systemic risk}

Assessing the systemic risk of similar technologies sometimes reveals significant variation. The analysis and

\footnotetext{
${ }^{11}$ The EESS described in Current Electrical Energy Supply has excess production capacity. It is not in $u$ as it does not meet the user requirements. Generation overcapacities are discussed in Substantial Systemic Risk.
}

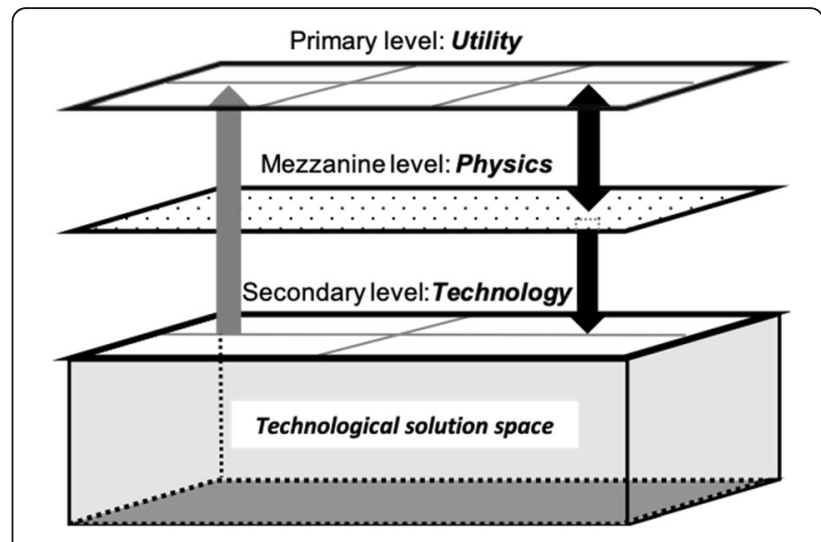

Fig. 9 Model extension by the technological solution set $\left(\Omega_{u}\right)$

evaluation of risks in engineering is therefore extensively researched [30].

The present analysis predicts fundamental systemic effects of risk in national EESS. Central to this assessment is a substantial system risk with two subcategories:

1. Sudden change from normal operating state to a system OFF state

2. Duration of a system OFF state

The substantial systemic risk has an associated likelihood $r_{s}$; there are also likelihoods for the two subcategories, $r_{1}, r_{2}$ :

$$
r_{s}=r_{1} \cdot r_{2}
$$

\section{Risk factor $r_{1}$}

In an EESS, the sudden change from a normal operating state to a system OFF state implies rapid loss of function in a connected electrical element; here the failure of a national macrocell is considered. Combining Eq. 7 and the failure factor $\mu \in[0,1]$, with $t_{0}, t_{0}^{\prime} \in T$ , yields

Table 1 Component representation of the state vectors of a national EESS

\begin{tabular}{ll}
\hline $\boldsymbol{u}_{0} \in \Omega_{u_{0}}$ & $\boldsymbol{u}_{0}=\left(0<i_{0}^{\prime}<i_{0} ; 0<n_{0}<\frac{1}{2} j_{0}^{*} ; j_{0}^{*}=i_{0}-i_{0}^{\prime} ; 0<k_{0}^{*}<\frac{1}{2} j_{0}^{*}\right)$ \\
& Basis: polychromatic system consisting of base modules I \\
& and II \\
$\boldsymbol{u}_{i} \in \Omega_{u_{l}}$ and $\boldsymbol{u}_{/}$ & $\boldsymbol{u}_{\mid}=\left(i_{0}^{\prime}=i_{0} ; n_{0}=0 ; j_{0}^{*}=0 ; k_{0}^{*}=0\right)$ \\
$\notin \Omega_{u_{0}}$ & Basis: monochromatic system from base module I \\
$\boldsymbol{u}_{\| \in \Omega_{u_{\|}}}$and & $\begin{array}{l}\boldsymbol{u}_{\|}=\left(i_{0}^{\prime}=0 ; n_{0}=1 ; j_{0}^{*}=i_{0} ; k_{0}^{*} \geq 1\right) \\
\boldsymbol{u}_{\| /} \notin \Omega_{u_{0}}\end{array}$ \\
\hline
\end{tabular}




$$
\frac{\partial E_{\text {Nat. }}^{D}\left(t_{0}\right)}{\partial t} \rightarrow-\infty, \text { and } E_{\text {Nat. }}^{S}\left(t_{0}^{\prime}\right)<\mu \cdot E_{\text {Nat. }}^{D}\left(t_{0}^{\prime}\right)
$$

given that the signal propagates with the speed of light in the medium and where a $5 \%$ upper bound is been assumed $(\mu \in[0 ; 0.05])$. System states where at least $0.1 \%$ of the total users (total $>10^{6}$ ) are modeled independently and are collective cell structures, subject to statistical conditions.

Determining the risk factor

\begin{tabular}{lll}
\hline $\mathbf{u}_{i} \in \Omega_{u_{l}}$ & Basis: monochromatic system \\
Risk factor & $r_{1,1}=0$ \\
\hline
\end{tabular}

The likelihood for microcell failure is taken as $p_{i}=\frac{5}{365}$, an interruption likelihood of 5 days per year. The lower limit for a national system with $i_{0}=10^{6}$ users is the statistical failure of about 15,000 microcells per day, with a failure rate of $1.5 \%$. This is assumed to represent $1.5 \%$ of energy demand. Then, $E^{S}=0.985 \cdot E^{D}$ and, according to Eq. 27, the system is not in the OFF state. The extreme situation would be for all cells to switch to the OFF state at the same time. The likelihood of this is

$$
P_{i_{0}}=p_{i}^{i_{0}}=\left(\frac{5}{365}\right)^{10^{6}}=0 .
$$

A national EESS in system state $u_{I}$ cannot entirely lose functionality in the sense of a system OFF state.

\begin{tabular}{lll}
\hline 1.2 & $\boldsymbol{u}_{\|} \in \Omega_{u_{\|}}$ & Basis: monochromatic system \\
Risk factor & $r_{1,2}=1$
\end{tabular}

The macrocell is completely connected and thus not a statistical collective. Maximum loss of function occurs when the node location vector is absent from the base set (cf. Technological Possibility Solution Space; Additional file 1). Propagation occurs at the speed of light in the relevant medium, as has been observed in real interruptions. ${ }^{12}$

A national EESS in system state $u_{\mathrm{II}}$ can enter a system OFF state (Fig. 9).

\begin{tabular}{lll}
\hline 1.3 & $\boldsymbol{u}_{0} \in \Omega_{u_{0}}$ & Basis: polychromatic system \\
& Risk factor & $0<r_{1,3}\left(u_{0}\right)<1$ \\
\hline
\end{tabular}

The distribution of micro- and macrocells in a system state underlies the overall risk factor. The microcell contribution can be assumed to be zero, as it is

\footnotetext{
${ }^{12}$ UCTE grid area interruption of 4.11.2006: severe frequency drop originating in West zone; $\frac{\Delta f}{\Delta t} \approx \frac{1 \mathrm{~Hz}}{30 \mathrm{~s}}$ [35]. Interpolating from the lowlimit frequency of $47.5 \mathrm{~Hz}$ indicates that for up to $90 \mathrm{~s}$, all power plants were disconnected.
}

guaranteed to be smaller than in the state $\left(\boldsymbol{u}_{I}\right)$. The contribution from macrocells is again determined by their number and size (cf. Defining Social Sustainability). The risk factor $r_{1,3}$ depends on the system state $\boldsymbol{u}_{0}$.

To set bounds on the risk factor, two boundary cases are considered:

- In the first case, the number of independent microcells approaches $i_{0}^{\prime} \rightarrow i_{0}$ so that the system approaches the state $\boldsymbol{u}_{\mathrm{I}}$, i.e., $r_{1,3} \rightarrow 0$

- In the second case, the macrocells approach $n_{0} \rightarrow 1$ and the number of non-parallel microcells disappears, $i_{0}^{\prime} \rightarrow 0$, so that the system approaches $u_{\mathrm{II}}$, i.e., $r_{1,3} \rightarrow 1$

\section{Risk factor $r_{2}$}

The next subject is the duration of OFF states, that is, the period of time from the system entering a function-loss OFF state to the recovery of normal operation. Here, OFF states that last longer than $24 \mathrm{~h}$ are considered. Such interruptions are caused by fundamental system impairments. Equation 27 results in the following condition

$$
\begin{gathered}
\forall t \in\left[t_{0} ; t_{1}\right): E^{S}(t)<\mu \cdot E^{D}(t) \text { and } t_{1} \\
>t_{0}+24 h .
\end{gathered}
$$

There are various ways of recovering operation (Fig. 10).

- Redundancies are existing system parts that can compensate for planned or unplanned failures. Redundancy support is generally effective for less than $24 \mathrm{~h}$. Redundancies are not further considered here.

- Parallel systems are entire existing systems that are capable of establishing a regular operating state without accessing the OFF-state system. Recovery is exponential for large technological systems with a time constant $\tau$. Recovery time is greater than $24 \mathrm{~h}$.

- Reparation is the restoration of an initial state and is divided into two model stages. Until $t_{1}$, defective facility elements are recovered with no intervening supply (dead time). After $t_{1}$, further elements are repaired and supply is exponentially resumed.

Recovery time is greater than $24 \mathrm{~h}$.

Dead times and time constants characterize parallel systems and recovery strategies.

Determining the risk factor

\begin{tabular}{lll}
\hline $\boldsymbol{u}_{\mathbf{l}} \in \Omega_{u_{\mathbf{l}}}$ & Basis: monochromatic system \\
Risk factor & $r_{2,1}=0$ \\
\hline
\end{tabular}

The risk factor $r_{1,1}$ of a national macrocell consisting only of microcells is zero, and the system cannot change to a system OFF state. 


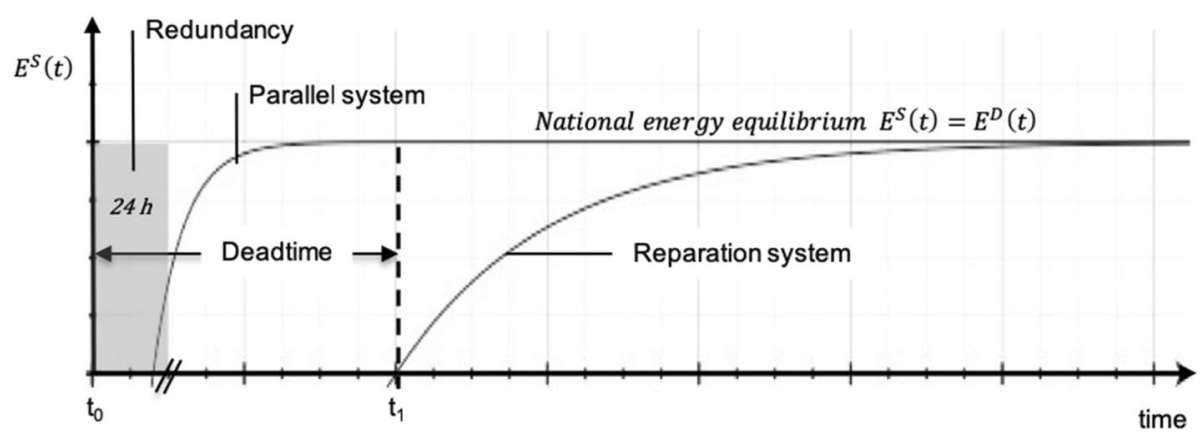

Fig. 10 Recovery paths to the national energy equilibrium level

\begin{tabular}{lll}
\hline 2.2 & $\boldsymbol{u}_{\|} \in \Omega_{u_{l}}$ & Basis: monochromatic system \\
& Risk factor & $r_{2,2}=1$ \\
\hline
\end{tabular}

A national technological macrocell may completely lose function and can therefore satisfy Eq. 28. A parallel system in this case would be a second national electricity grid capable of assuming the supply task given the requirements above. The grids operate under conditions of natural monopoly, in which the cost function is subadditive [31]. This means that for economic reasons, there is no parallel option for a national EESS.

The remaining strategy is reparation. For an order-ofmagnitude estimation, only the dead time has to be considered. If the fundamental impairments are mechanical in nature, a low estimate for dead time is at least 6 months. This represents manufacturing or production time for the failed plant elements and is already signifi$\operatorname{cant}^{13}$; the entire repair takes significantly more time. The conclusion is that a national EESS in $u_{\text {II }}$ can assume a system OFF state of inestimable duration.

\begin{tabular}{lll}
\hline 2.3 & $\boldsymbol{u}_{0} \in \Omega_{u_{0}}$ & Basis: polychromatic system \\
& Risk factor & $0<r_{2,3}\left(u_{0}\right)<1$ \\
\hline
\end{tabular}

A starting point is the properties of $r_{1,3}$. Boundary conditions can be deduced as follows:

- In one case, the number of independent technological microcells approaches the number of users $i_{0}^{\prime} \rightarrow i_{0}$; states with $r_{2,1}$ approach zero

- In another case, the system approaches a national macrocell state $n_{0} \rightarrow 1$. The system approaches the state $r_{2,2}$, i.e., $r_{2,3}$ tend to 1

Here, too, risk factors depend on system state.

\footnotetext{
${ }^{13}$ For Republic of Austria, quantifiable damage would amount to at least $€ 180$ billion [21].
}

\section{Risk factor $r_{s}$}

Table 2 lists substantial risk for system states $\left(u_{\mathrm{I}}, u_{\mathrm{II}}\right)$. The state consisting only of a national macrocell has the highest risk-the system which fully utilizes the two physical options (cf. Current Electrical Energy Supply; this is the case for the current EESS). All other states have lower risks, but it is nonetheless a broad spectrum. A national EESS consisting only of individual microcells has zero substantial risk.

As the substantial risk factor distinguishes system states technologically, it represents another structural variable (cf. Technological Possibility Solution Space).

$S_{6}$-substantial risk factor, $r_{s} \rightarrow 0$

The new structure vector describes the system technologically, specifically the degree of interconnections in the grid structure in a national macrocell. It emphasizes functional loss of macrocells.

The substantial risk factor $S^{*}$ is extended by component $S_{6}$ to complete the technological structure vector $S^{* * *}$.

Key point 15: Risk determination for a sudden change from normal operating state to system OFF state

Key point 16: Risk determination for the duration of a system OFF state

Key point 17: Risk determination for an existing substantial system risk

Key point 18: Definition of substantial risk factor as sixth technological structural variable for national EESS

Table 2 Substantial risk factors for system states

\begin{tabular}{llll}
\hline System state & & & \\
\hline Risk factor & $\boldsymbol{u}_{i} \in \Omega_{u_{\boldsymbol{l}}}$ & $\boldsymbol{u}_{\| /} \in \Omega_{u_{\|}}$ & $\boldsymbol{u}_{0} \in \Omega_{u_{0}}$ \\
\hline$r_{1}$ & $r_{1,1}=0$ & $r_{1,2}=1$ & $r_{1,3}\left(u_{0}\right) \in(0 ; 1)$ \\
$r_{2}$ & $r_{2,1}=0$ & $r_{2,2}=1$ & $r_{2,3}\left(u_{0}\right) \in(0 ; 1)$ \\
$r_{s}=r_{1} \cdot r_{2}$ & $r_{s, u_{1}}=0$ & $r_{s, u_{\|}}=1$ & $r_{s, u_{0}} \in(0 ; 1)$ \\
\hline
\end{tabular}




\section{Defining social sustainability System states}

A sustainability dimension is incorporated through a new technological and economic availability. Availability is understood in the sense of [32] and represents the utilization potential of the system. The sustainability component now added to the state vectors $u \in \Omega_{u}$ equals the product from the availability parameter $v_{t v}$ and the total load for a national macrocell $E_{\text {Nat. }}^{D}(t)$ from Eq. 7. The new sustainability component is

$$
\boldsymbol{v}=\left(i_{0}^{\prime}, n_{0} ; j_{0}^{*} ; k_{0}^{*} ; v_{t v} \cdot E_{\mathrm{Nat} .}^{D}(t)\right)
$$

with

$$
\boldsymbol{v} \in \Omega \text { and } \Omega_{u} \subset \Omega \text {. }
$$

Availability is related to risk through the substantial risk factor $r_{s}$ :

$$
v_{t v}=1-r_{s}
$$

with

$$
v_{t v} \in[0 ; 1] .
$$

The sustainability of a load on a national EESS now depends on the technology used. The limiting cases (cf. Table 2) of substantial risk $\left(r_{s}=0 ; r_{s}=1\right)$ are sustainable for $\boldsymbol{v}_{\mathrm{I}}=\left(i_{0}^{\prime}, n_{0} ; j_{0}^{*} ; k_{0}^{*} ; 1\right)$ and unsustainable for $\boldsymbol{v}_{\mathrm{II}}=\left(i_{0}^{\prime}\right.$, $\left.n_{0} ; j_{0}^{*} ; k_{0}^{*} ; 0\right)$.

Existence of a boundary between states with quantifiable risk and non-quantifiable risk is implied by the completeness of the technological solution set $\Omega_{u}$ (Fig. 11).

The determination of this sustainability limit (sustainable availability limit) is an economic problem (cf. Appendix 1).
Due to considerable variation in the number and size of macrocells in the various system states, $\boldsymbol{u}_{0} \in$ $\Omega_{u_{0}}$, there is a spatial dimension to sustainability. The sustainability components of distinct macrocells must be distinguished, on the basis of Eq. 5. This means that

$$
v_{t v} \cdot E_{j_{0}}^{D}(t)=\sum_{n=1}^{n_{0}} v_{t v, n} \cdot E_{n}^{D}(t)
$$

which introduces regional sustainability into the national EESS. Differences can have historical reasons or arise from future-oriented processes (innovation, transformation).

\section{Energy quantities and system states}

The energy balances given by the user requirements cannot be ideally satisfied in the operation of real energy cells. Deviations due to supply reductions or interruptions due to faults are quantitatively expressed by a supply factor $\lambda \in[0 ; 1]$.

For the $i$ th user of the $i$ th microcell, the individual energy function becomes (for simplicity, $t^{\prime}=t$ ):

$$
E_{i}^{S}(t) \geq \lambda_{i}^{-} \cdot E_{i}^{D}(t)
$$

with

$$
\lambda_{i}^{-} \leq 1
$$

The economic interests of a national macrocell are expressed by the energy function

$$
E_{\mathrm{Nat} .}^{S}(t) \geq \lambda_{\min }^{-} \cdot E_{\mathrm{Nat}}^{D}
$$

with

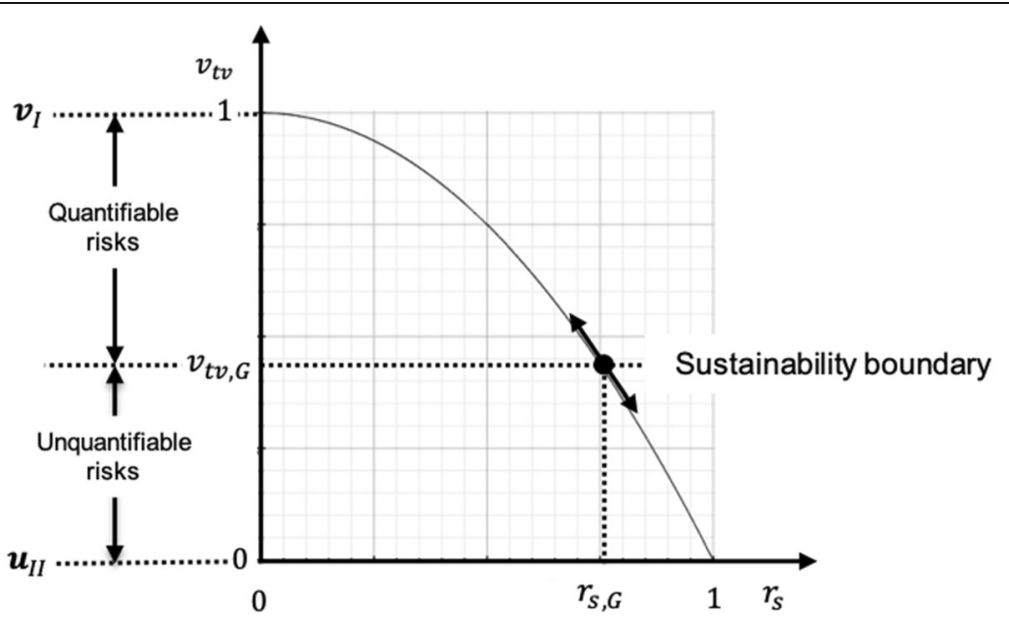

Fig. 11 Boundary due to the sustainability limit in the state model of an EESS. As an example, $\left(r_{1}, r_{2}\right)$ are assumed linear 


$$
\lambda_{\min }^{-} \leq 1
$$

A utilitarian definition of utility implies a boundary condition

$$
\lambda_{\min }^{-} \leq \lambda_{i}^{-} \leq 1
$$

$\lambda_{i}^{+}, \lambda_{\max }^{+}>1$ are states with generation overcapacities; they do not alter $r_{s}$. The energy demand $E_{\text {Nat. }}^{D}(t)$ from Eq. 33 can be approximated by the product of a freely selectable standardized distribution function $h(t)$ and an annual reference energy quantity $E_{T_{\text {Ref }}}^{D}$. The energy relation for supply energy is then

$$
E_{\text {Nat. }}^{S} \geq \lambda_{\text {min }}^{-} \cdot E_{\text {Nat. }}^{D}(t) \approx \lambda_{\text {min }}^{-} \cdot h(t) \leq \cdot E_{T_{\text {Ref }}}^{D}
$$

This is the basis for predicting the demand. Information about the supply status in the microcells is necessary for the operation of a national EESS. In addition to passive analysis, active prognoses can be made about future energy demand and microcells can be centrally controlled in an interruption (i.e., a complete loss of function/blackout). For this, there is smart meter technology, ${ }^{14}$ now a key EU energy policy issue [33].

The energy quantities from Eq. 33 need to be connected to the sustainable system states of Eq. 29. This is expressed in the coupling relation

$$
\lambda_{\text {min }}^{-}=g(x) \cdot v_{t v}\left(r_{s}\right)=g(x) \cdot\left(1-r_{s}\right)
$$

with weighting function $g(x)$, shown in Fig. 12. For simplicity, $g(x) \equiv 1$.

The above builds a technological-economic foundation for the design of a sustainable national EESS.

The process for defining boundary conditions should have at its center utilitarian benefit and can be devised by the user community. Ensuring the transparency of this process is a social, economic, and technical challenge which needs further investigation (Appendix 2 ). The prerequisite for sustainability is that system variability must be contained within the technology and not affect the energy demand and supply.

\footnotetext{
${ }^{14}$ Functions of a "smart meter": 1 . Determine current demand2. Record current supply3. Predict future demand4. Monitor each user's availability5. Active system control in the grid areas, in particular, for macrocell failure, e.g., blackout control
}

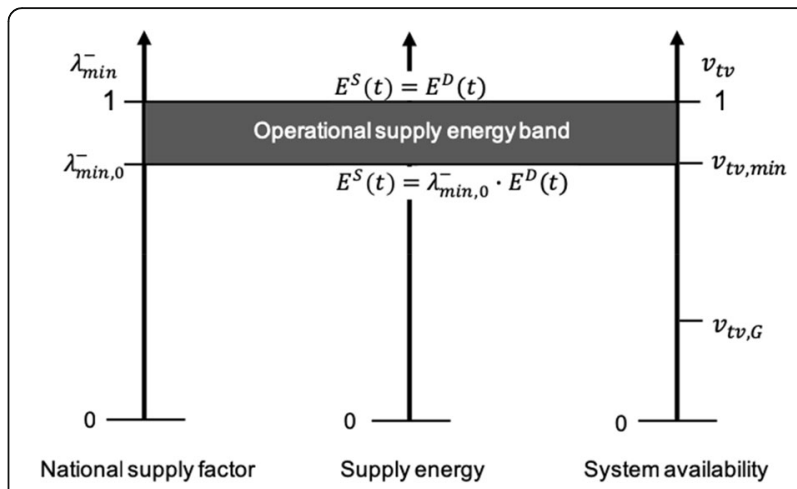

\begin{tabular}{|c|c|}
\hline EESS & Electrical energy supply system \\
\hline RF & Regression function \\
\hline$I \subset N_{0}$ & With $i, i_{0}, i^{\prime}, i_{0} \in l$ and $i, i_{0}^{\prime} \leq i_{0}, i \leq i_{0}^{\prime}$ \\
\hline$T \subset R$ & With $t, t^{\prime}, \Delta t, \Delta t_{R \prime} t_{A}, t_{E}, \tau \in T$ and $\Delta t=t^{\prime}-t$ \\
\hline$N \subset R^{3}$ & With $x_{i}, x_{i}^{\prime}, x_{j}, x_{n_{0}} \in N$, pairwise coprime \\
\hline$E^{D}\left(t, x_{i}\right)$ & Energy demand function; short form $E_{i}^{N}(t)$ \\
\hline$E_{\max }^{D}\left(x_{i}\right)$ & Maximum energy demand; short form $E_{\max , i}^{N}(t)$ \\
\hline$f_{i}^{D}(t)$ & Time-dependent behavior of user $i$ \\
\hline$E^{S}\left(t, x_{i}\right)$ & Energy supply function; short form $E_{i}^{B}(t)$ \\
\hline$E_{j_{0}}^{D} \frac{(t)}{E_{j_{0}}^{S}}(t)$ & Bundled energy demand/supply of $j_{0}$ microcells \\
\hline$E_{\text {Nat. }}^{D} \frac{(t)}{E_{\text {Nat. }}^{s}}(t)$ & Energy demand/supply function of a national macrocell \\
\hline u & Energy density of the electromagnetic field \\
\hline$s$ & Poynting vector \\
\hline$J$ & Current density \\
\hline$E$ & Electric field strength \\
\hline$H$ & Magnetic field strength \\
\hline$\rho$ & Electrical charge density \\
\hline$\frac{c_{0}}{c}$ & Speed of light in vacuum/in a medium \\
\hline$E_{i}^{S T}$ & Stationary supply component of the ith microcell \\
\hline$c_{i} \in R$ & Stationary state constant of the ith microcell \\
\hline$E_{j_{0}}^{S T}$ & Stationary supply constant of a macrocell \\
\hline$P^{S}\left(t, x_{i}\right)$ & Output power of the ith source; short form $P_{i}^{B}(t)$ \\
\hline$P_{i}^{D_{\max }}$ & Maximum load (power consumption) of the ith microcell \\
\hline$P_{i}^{S_{\max }}$ & Maximum supply (power generation) of the ith microcell \\
\hline$\cdot P^{S}\left(t, x_{i}\right)$ & Power dynamics of the ith microcell; short form $\cdot P_{i}^{B}(t)$ \\
\hline$P\left(j_{0}\right)$ & Total power from $j_{0}$ microcells \\
\hline$P\left(k_{0}\right)$ & Total power from $k_{0}$ current sources \\
\hline
\end{tabular}

Fig. 12 Energy band of a national macrocell at a given time

\section{Appendix 1}

Table 3 List of abbreviations 
Table 3 List of abbreviations (Continued)

\begin{tabular}{|c|c|}
\hline$\wp_{\text {macrocell }}^{N}$ & $\begin{array}{l}\text { Maximum load of a macrocell, analogous to power } \\
\text { generation }\end{array}$ \\
\hline$\wp_{\text {Nat. }}^{N}$ & $\begin{array}{l}\text { Maximum load of a national macro cell, analogous to } \\
\text { power generation }\end{array}$ \\
\hline$S_{1}, \ldots, S_{5}$ & Structure variables, components of $S^{*}$ \\
\hline$S^{*} \in R^{5}$ & Technological structure vector \\
\hline$\Delta t_{r_{i}}$ & Time shift in the ith microcell due to the relativity principle \\
\hline$\Delta t_{s_{i}}$ & Time shift in the ith microcell considering real sources \\
\hline$\Delta t_{j_{0}}$ & Total time delay within a macrocell of $j_{0}$ microcells \\
\hline$J \subset N_{0}$ & With $j, j_{0} \in J$ and $j \leq j_{0}$ \\
\hline$K \subset N_{0}$ & With $k, k_{0} \in K$ and $k \leq k_{0}$ \\
\hline$N \subset N_{0}$ & With $n, n_{0} \in N$ and $n \leq n_{0}$ \\
\hline$(N, d)$ & Metric space on the set $N$ with metric $d$ \\
\hline$\sigma$ & Electrical conductivity \\
\hline$\Omega_{u} \subset R^{4}$ & Technological solution space with $\boldsymbol{u} \in \Omega_{u}$ \\
\hline$\Omega_{u_{0}}, \Omega_{u_{l}}, \Omega_{u_{\|}}$ & Subsets of the technological solution space \\
\hline LE & Unit of length \\
\hline$r_{s}$ & Substantial risk factor \\
\hline$r_{1}, r_{2}$ & Sub-risk factors \\
\hline$\mu$ & Failure factor \\
\hline$p_{i}$ & Failure likelihood of the ith microcell \\
\hline$P_{i_{0}}$ & Failure likelihood of a macrocell with $i_{0}$ users \\
\hline $\boldsymbol{S}^{* *} \in R^{6}$ & $\begin{array}{l}\text { Extension of the structure vector } S^{*} \text { with the substantial } \\
\text { risk factor }\end{array}$ \\
\hline$S_{6}$ & Structure variable for the substantial risk factor \\
\hline$v_{t v}$ & Availability \\
\hline$v_{t v, B}$ & Sustainability boundary; sustainable availability boundary \\
\hline$v_{t v} \cdot E_{\text {Nat. }}^{D}(t)$ & National sustainability \\
\hline$v_{t v, n} \cdot E_{n}^{D}(t)$ & Regional sustainability in a macrocell \\
\hline$v$ & State vector with sustainability component \\
\hline$\Omega \in R^{5}$ & Sustainable technological solution set with \\
\hline$E_{T_{\text {Ref. }}^{N}}$ & Annual energy demand in a reference year \\
\hline$\lambda_{i}^{-}$ & ith supply factor \\
\hline$\lambda_{\min }^{-}$ & National supply factor \\
\hline$h(t)$ & Distribution of annual energy demand with $\int_{t_{0}}^{t_{0}+365} h(t) d t=1$ \\
\hline$g(x) \in[0 ; 1]$ & Weights between $\lambda_{\min }^{-}$and $r_{s}$ \\
\hline$E_{T_{\text {Ref. }}^{D}}$ & $\begin{array}{l}\text { Annual reference energy arbitrary initial value } \int_{t_{0}}^{t_{0}+365} E^{D}(t) \\
d t\end{array}$ \\
\hline
\end{tabular}

\section{Appendix 2}

Table 4 Follow-up themes

Social opportunities and risks of pervasive use of electrical power

Gross domestic product: country-specific direct and indirect effects of electrical energy for products and services

Entropy of national electrical energy supply systems

Social effects from municipalization/nationalization responses to technological and economic costs in the national EESS

Quantitative determination of a sustainability boundary for the national EESS

Quantitative determination of a weighting function for operational supply energy values and technological system availability

A basis for user decisions on the establishment of national contributions Sociological effects of electricity storage in national EESS

Technological effects of electricity storage in national EESS

Incorporating user requirements into national legislation

Timing and process of transformation of a national EESS

\section{Supplementary information}

Supplementary information accompanies this paper at https://doi.org/10. 1186/s13705-019-0221-4.

Additional file 1. Mathematical and physical foundation of grid structure. Additional file 2. State vectors and grid spectra.

\section{Acknowledgements}

Not applicable

\section{Authors' contributions}

The author wrote, read, and approved the final manuscript.

\section{Authors' information}

Link to author's website: http://www.es.mw.tum.de/en/staff/visiting-lecturers/ benthaus/

\section{Funding}

No external funding

\section{Availability of data and materials}

All data generated or analyzed during this study are included in this published article.

\section{Ethics approval and consent to participate}

Not applicable

\section{Consent for publication}

Not applicable

\section{Competing interests}

The author declares that he has no competing interests.

Received: 11 January 2019 Accepted: 13 September 2019

Published online: 23 December 2019

\section{References}

1. Dyckhoff H (1994) Betriebliche Produktion - Theoretische Grundlagen Einer Umweltorientierten Produktionswirtschaft, 2nd edn. Springer sec. A § 2.2.3. Springer-Verlag Berlin Heidelberg GmbH.

2. Frankenia W (2017) Ethics, 6th edn. Springer: Springer Fachmedien Wiesbaden GmbH. pp 35-39 
3. Dyckhoff, H. (1994) Betriebliche Produktion - Theoretische Grundlagen Einer Umweltorientierten Produktionswirtschaft. 2nd ed. Springer chap. A § 3.3

4. Lenin V (1920) Werke, vol 31, p 513 (1966 German translation)

5. Stier, B. (1999) Staat Und Strom. vol. 10 Technik und Arbeit Landesmuseum für Technik und Arbeit in Mannheim

6. Index Mundi (2018) Country Facts. https://www.indexmundi.com

7. EIA (2018) Us Energy Information Administration. https:/www.eia.gov/

8. Global Economy (2018) Economic Indicators For Over 200 Countries. https:// de.theglobaleconomy.com

9. Löchel C (2018) Fischer Weltalmanach. Fischer Publishing House. Fischer Taschenbuchverlag, Fischer Verlag GmbH, Frankfurt am Main

10. Casazza J, Delea F (2010) Understanding Electric Power Systems, 2nd edn. Wiley chap. 1, 2, 3, 6, 7. Hokoken: Wiley.

11. Oeding D, Oswald B (2011) Electric power plants and grids, 7th edn. Springer chap. 1, 2, 5, 6, 12, 14, 15, 18. Dordrecht London New York: Springer Heidelberg.

12. Official Journal Of The European Union (2009) Regulation (Ec) No 714/2009 Of The European Parliament And Of The Council On Conditions For Access To The Network For Cross-Border Exchanges In Electricity And Repealing Regulation (Ec) No 1228/2003

13. Official Journal Of The European Union (2009) Directive 2009/72/Ec Of The European Parliament And Of The Council Concerning Common Rules For The Internal Market In Electricity

14. BNETZA (2017) Kennzahlen Der Versorgungsunterbrechungen Strom

15. Council of European Energy Regulators (2016) 6th CEER Benchmarking Report On The Quality Of Electricity And Gas Supply

16. Oeding D, Oswald B (2011) Electric power plants and grids, 7th edn. Springer chap. 15. Dordrecht London New York: Springer Heidelberg.

17. Michel M (2011) Power electronics, 5th edn. Springer chap. 8. Dordrecht London New York: Springer Heidelberg.

18. Casazza J, Delea F (2010) Understanding Electric Power Systems, 2nd edn. Wiley chap. 1, 3, 9. Hokoken: Wiley.

19. ENTSO-E (2018) Continuing frequency deviation in the continental european power system originating in Serbia/Kosovo: political solution urgently needed in addition to technical

20. FOCP (2015) Bundesamt Für Bevölkerungsschutz. Nationale Gefährdungsanalyse - Ausfall Stromversorgung Schweizerische Eidgenossenschaft

21. Austrian Civil Defence Association (2017) Blackout Advice. www. zivilschutzverband.at

22. Landau L, Lifshitz E (2014) Lehrbuch Der Theoretischen Physik, vol 2, 12th edn. Europa-Lehrmittel chap. 1-6. (based on 1998 Russian 7th ed.). Haan-Gruiten.

23. Jackson J (2014) Klassische Elektrodynamik, 5th edn. De Gruyter chap. 5-7

24. Fano, R.; Chu,L;; Adler, R. (1968) Electromagnetic Fields. Energy and Forces MIT Press chap. 4-9. Cambridge.

25. Jackson J (2014) Klassische Elektrodynamik, 5th edn. De Gruyter chap. 6.7. Berlin.

26. Jackson J (2014) Klassische Elektrodynamik, 5th edn. De Gruyter chap. 6.9. Berlin.

27. Jackson J (2014) Klassische Elektrodynamik, 5th edn. De Gruyter chap. 5. Berlin.

28. Jackson J (2014) Klassische Elektrodynamik, 5th edn. De Gruyter sec 5.15 Berlin.

29. Jackson J (2014) Klassische Elektrodynamik, 5th edn. De Gruyter chap. 6. Berlin.

30. Preiss R (2017) Methods of risk analysis in engineering, 2nd edn. TÜV Austria Akademie GmbH. Wien.

31. Mankiw NG (2014) Principles of economics, 7th edn. South Western, p 302

32. Eberlin S, Hock B (2014) Zuverlässigkeit Und Verfügbarkeit Technischer Systeme. Springer Vieweg, p 65

33. Official Journal Of The European Union (2012) Commission recommendation on preparation for the deployment of smart metering (2012/148/Eu)

34. Eberlin S, Hock B (2014) Zuverlässigkeit Und Verfügbarkeit Technischer Systeme. Springer Vieweg

35. BNETZA (2007) On the system disturbance in the German and European power system on 4th of November 2006. Federal Network Agency for Electricity, Gas, Telecommunications, and Railways, p 11. Bonn.

\section{Publisher's Note}

Springer Nature remains neutral with regard to jurisdictional claims in published maps and institutional affiliations.

\section{Ready to submit your research? Choose BMC and benefit from:}

- fast, convenient online submission

- thorough peer review by experienced researchers in your field

- rapid publication on acceptance

- support for research data, including large and complex data types

- gold Open Access which fosters wider collaboration and increased citations

- maximum visibility for your research: over $100 \mathrm{M}$ website views per year

At BMC, research is always in progress.

Learn more biomedcentral.com/submissions 